\title{
Cultural influences on knowledge sharing through online communities of practice
}

\author{
Alexandre Ardichvili, Martin Maurer, Wei Li, Tim Wentling and Reed Stuedemann
}

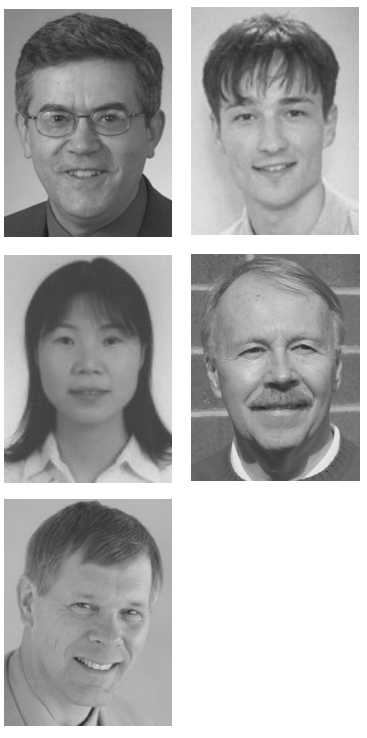

(Information about the authors can be found at the end of the article.)

\begin{abstract}
Purpose - The purpose of this study is to explore cultural factors influencing knowledge sharing strategies in virtual communities of practice.

Design/methodology/approach - A qualitative research design was employed. Data collection was based on in-depth interviews. The authors assumed that such factors as degree of collectivism, competitiveness, the importance of saving face, in-group orientation, attention paid to power and hierarchy, and culture-specific preferences for communication modes, would explain differences in knowledge seeking and sharing patterns.
\end{abstract}

Findings - The results showed that these factors had different levels of importance among employees in the three participating countries. The issue of saving face was less important than expected in China. Modesty requirements as well as a high degree of competitiveness among employees were found to be serious barriers to information sharing in China, but not in Russia and Brazil. Perceived differences in power and hierarchy seemed to be less critical in all three countries than initially assumed.

Research limitations/implications - Since this study was conducted among the online community members of Caterpillar Inc., the results could be affected by factors unique to this specific case. Thus, future research should investigate the influence of other factors such as the organizational culture, or occupational groups on knowledge sharing strategies.

Practical implications - Before any introduction of country-specific knowledge sharing systems, a cultural needs assessment should be conducted.

Originality/value - The impact of national culture factors on knowledge sharing has been largely neglected in the literature, and the findings will assist knowledge managers charged with the design of flexible knowledge management systems.

Keywords Knowledge management, Culture, Knowledge sharing

Paper type Research paper

\section{Introduction}

Knowledge management is a complex socio-technical system that encompasses various forms of knowledge generation, storage, representation, and sharing. Specific features and functionality of knowledge management (KM) systems are always based on assumptions inherent in cultural backgrounds of their designers and managers. However, if these systems are used by people with professional or national culture backgrounds, which differ from those of the designers, features intended to support knowledge generation and sharing may actually inhibit these processes (Branch, 1997).

Recent research on organizational learning and knowledge creation indicates that knowledge sharing, communication, and learning in organizations are profoundly influenced by cultural values of individual employees (Hofstede, 2001; Hambrick et al., 1998; Hutchings and Michailova, 2004; Pfeffer and Sutton, 2000). Furthermore, studies of cognitive strategies and methods of learning and knowledge generation suggest that cognitive styles differ by national and ethnic cultures (Korac-Kakabadze and Kouzmin, 1999). Different ethnic groups have been found to have different preferences for symbolic 


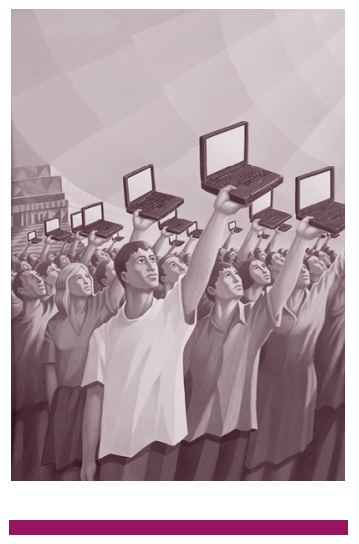

versus semantic learning and cognition, and for different forms of verbal and visual presentation of information and learning content (Ginsburg et al., 1981).

Therefore, determining how different or similar knowledge sharing strategies of representatives of various national and ethnic groups are is one of the most important pre-requisites for successful design of flexible KM systems, adoptable to styles and preferences of employees in multinational, globally-dispersed corporations. Such research will help to make sure that knowledge management system design and development decisions are consistent with the employees' values, perceptions, preferred styles of communication, and cognitive and learning styles, which are shaped by particular cultural contexts.

Despite growing recognition of the importance of cultural influences on knowledge management, there is a lack of related empirical research. To address this gap this qualitative study, conducted over a period of 12 months at overseas offices of Caterpillar, attempted to answer the following research questions:

- How do differences in cultural values, assumptions and preferences affect the way employees in overseas offices access and share professional knowledge?

- What are the employees' perceptions of preferred approaches to information seeking, knowledge representation and sharing?

- What are culture-specific barriers to knowledge sharing?

Although some of the study findings are general in nature, and apply to knowledge sharing practices in general, the main emphasis of this particular study was on knowledge sharing through an online corporate knowledge sharing system. Therefore, the study findings will be of special interest to knowledge managers, interested in implementing corporate-wide online knowledge exchange systems, and online communities of practice.

\section{Theoretical framework}

\section{Knowledge management and communities of practice}

In recent years communities of practice (CoPs) have gained increasing popularity as a way to manage the human and social aspects of knowledge creation and dissemination within organizations, and have also received significant attention in the knowledge management literature (Ardichvili et al., 2003; Wenger et al., 2002; Gourlay, 2001; Walsham, 2001; Wasko and Faraj, 2000; Davenport and Prusak, 1998). The term community of practice was coined by Lave and Wenger (1991) who define it as ". . . an activity system about which participants share understandings concerning what they are doing and what that means in their lives and for their community" (p. 98). Central to communities of practice theory is an assumption that less experienced members of the community learn from social interactions with more experienced members and experts of a specific knowledge domain (Lave and Wenger, 1991). Newcomers initially perform "peripheral" or simple activities in the completion of a specific task, and over time take on more central tasks and roles to eventually become experts. This process of learning has been termed "legitimate peripheral participation" by Lave and Wenger (1991), and results in a continuum of expertise within a community of practice where some members participate more and others less actively and frequently. Wenger et al. (2002) assert that a CoP usually consists of a rather small core group, which actively participates in community interactions and assumes community leadership, usually the community experts and managers, a small active group consisting of members who participate quite frequently, but not as regularly as the core group members, and a large portion of community members who rarely participate (such members are called peripheral participants).

Perhaps the most widely recognized benefit of CoPs is their ability to allow for the generation and dissemination of tacit knowledge, that is, knowledge that is hard to communicate because it is mostly intuitive and embedded in a specific context (Nonaka, 1994; Polany, 1957). Because it is difficult for others to imitate or copy tacit knowledge, there is growing agreement that this type of knowledge is a key element in sustaining organizational

VOL. 10 NO. 12006 | JOURNAL OF KNOWLEDGE MANAGEMENT | PAGE 95 


\section{"Perhaps the most widely recognized benefit of CoPs is their ability to allow for the generation and dissemination of tacit knowledge."}

competitiveness (Liedtka, 1999; Davenport and Prusak, 1998). It has been argued that sharing and internalizing tacit knowledge requires active interaction among individuals, especially in the form of storytelling (Wenger et al., 2002; Brown and Duguid, 1991). This is where CoPs come in as a platform for such exchanges to take place.

For multinational organizations, faced with the challenge of disseminating organizational knowledge that resides in individuals and teams spread around the world, one of the best options for such exchanges is through online collaborative communication technologies. Thus, distributed virtual CoPs, which make use of such technologies, are becoming an increasingly popular way for knowledge sharing among geographically dispersed employees (Hildreth et al., 2000; Wenger et al., 2002).

It should not be surprising that the creation and transfer of knowledge across cultural boundaries creates additional challenges that need to be addressed in order to facilitate this process. For instance, Wenger et al. (2002) state that:

People's willingness to ask questions that reveal their "ignorance", disagree with others in public, contradict known experts, discuss their problems, follow others in the thread of conversation - all these behaviors vary greatly across cultures (p. 118).

Based on our review of literature we have identified several national culture characteristics expected to influence individuals' knowledge sharing patterns.

\section{Cross-cultural differences in knowledge sharing patterns}

Literature on knowledge transfer between units of multinational corporations as well as within joint ventures discusses various factors in international knowledge sharing (Gupta and Govindarajan, 1994, 2000; Inkpen and Dinur, 1998; Kogut and Zander, 1993; Mowery et al., 1996; Simonin, 1999). However, only very few recent studies have explicitly concentrated on the discussion of cultural factors, influencing knowledge management and transfer (Chow et al., 2000; Ford and Chan, 2003; Holden, 2001; Hutchings and Michailova, 2004). Bhagat et al. (2002) have made a significant contribution to this body of literature by providing a conceptual framework of international transfer of organizational knowledge, which we will refer to on several occasions.

In order to frame our study and examine the effect of national culture differences on knowledge sharing behaviors of Russian, Chinese and Brazilian employees, we specifically focused on several most commonly applied universal criteria in international comparisons of cultures (Hofstede, 2001; Trompenaars, 1994; Triandis, 1995).

Individualism - collectivism. The distinction between individualism and collectivism is undoubtedly the most frequently applied criterion in cross-cultural studies. Individualism describes the tendency of people to place personal goals ahead of the goals of a larger social group, such as the organization. On the other hand, individuals in collectivistic cultures tend to give priority to the goals of the larger collective or group they belong to (Hofstede, 2001), which often results in actions of individuals which serve the community or society (Trompenaars, 1994). A further distinction between individualism and collectivism was made on the basis of the definition of self (Triandis, 1995). Members of individualistic cultures see themselves as independent of others, whereas collectivists see themselves as interdependent with other members, in many cases with members of a specific in-group (the in-group vs out-group distinction will be discussed in more detail later). 
Bhagat et al. (2002) posit that members of collectivistic and individualistic cultures are characterized by distinctively different ways of processing information and constructing knowledge. For instance, in individualistic cultures (e.g. USA), individuals tend to see each piece of information independent of its context, emphasize information in written and codified form and are more likely to accept such information. On the other hand, members of collectivistic cultures (e.g. China, Brazil and Russia) look for contextual cues in information and tend to disregard information in writing (Bhagat et al., 2002). Hall's (1976) distinction between high- and low-context styles of communication further supports this claim. In high-context cultures, such as China, Brazil and Russia, people tend to rely more on the context of non-verbal actions and the environmental setting to convey meaning, and therefore tend to prefer communication media with high media-richness, such as face-to-face communication or phone calls. For members of low context cultures, such as the USA, meaning is not readily available from the environment because they tend not to learn how to perceive information from the environment. Consequently, in low-context cultures more emphasis is put on the written word, which leads to the conclusion that communication media low in media-richness, such as e-mails or online discussion boards will be more accepted.

In-group and out-group orientation. One additional consequence of the individualism and collectivism distinction deserves a separate discussion. It is the fact that collectivists tend to make a sharper differentiation between in-group and out-group members. In fact, Chow et al. (2000), comparing factors influencing knowledge sharing behaviors between US and Chinese managers, have found that Chinese nationals were much more reluctant to share with an out-group member than Americans. Hutchings and Michailova (2004), discussing the impact of group membership on knowledge sharing, indicate: "in China one's membership of in-groups affects all daily activities ..." and "is the source of identity, protection, and loyalty ..." (p. 87). They also point out that the same phenomenon is observed in Russia, where communal traditions ("obshina," or village commune) go back hundreds of years. Hutchins and Michailova cite Ashwin's (1996) work, which suggests that Russian workers strongly identify themselves with at least three levels of in-groups: the whole enterprise; the collective of common workers; and their specific work group.

The implication of the in-group versus out-group distinction is that collectivists are more likely to share what they know with their in-group members, thus attempting to serve the interest of the group instead of pursuing mere self-interest. Individualists, who do not have such strong affiliations with in-groups, may not be willing to share even within their immediate work collectives. At the same time, since strong in-group orientation is often accompanied by negative feelings towards out-groups (Ashwin, 1996), knowledge sharing on organization or inter-organization level could be significantly inhibited by this group orientation (Hutchings and Michailova, 2004).

Fear of loosing face. With regard to factors influencing information seeking behavior, the literature points towards a cultural attribute grounded in the individualism-collectivism distinction, namely the extent to which individuals try to gain face (Mianzigain) or avoid loosing face (Mianziloss) (Hwang et al., 2003). Hwang et al. (2003) conducting a study with undergraduate business students, found that individualism is positively related to Mianzigain, and that consequently individualists, in this case American students, were most likely to ask questions in class. This is because asking questions is a way to gain prestige and recognition (Mianzigain), and not just to gain knowledge. Surprisingly, the researchers did not find support for the hypothesis that collectivism is positively related with the fear of Mianziloss. However, this relationship was found to exist in the American individualistic sample. Nonetheless, Hwang et al. (2003) were able to confirm that in general individuals concerned with loosing Mianzi will be less likely to ask questions in class in order to avoid Mianziloss. Hwang et al. (2003) also found evidence that individuals who want to gain face will be more likely to use formal communication channels to show their knowledge and ability, while those who worry about losing face will prefer informal communication channels. An example of such use of informal communication channels would be students asking questions of the professor outside the classroom or informal discussions among students. 
Bansler and Havn (2003), who have conducted a longitudinal study of online sharing of best practices among middle managers inside a large European pharmaceutical company, found that one reason why many managers did not want to contribute to the intranet-based knowledge database was that they wanted to avoid giving the impression of bragging. Their findings suggested that letting other people know how knowledgeable one is was not considered good etiquette in that organization, and posting something online "was considered to be a form of boasting and an inappropriate self endorsement" (p. 161). The authors do not disclose whether this organization is located in a collectivist or individualist society, but other research suggests that modesty issues tend to be prevailing in collectivistic cultures (Kurman, 2003). Kurman defines modesty as "the public under-presentation of one's favorable traits and abilities" (p. 501). She specifically examined the relationship between modesty requirements and low self-enhancement in collectivistic cultures. Kurman found support for the notion that cultural restrictions, such as the requirement of displaying modesty, are mainly responsible for low self-enhancement found in certain collectivist cultures. We therefore assume that modesty not only explains low self-enhancement, but it may also account to some extent for collectivists' reluctance to actively participate in online community discussions, in order to avoid creating the impression of bragging.

The importance of status; power distance; horizontal and vertical cultures; and achievement and ascription-oriented cultures. Bhagat et al. (2002) include Triandis' (1995) distinction between vertical and horizontal cultures in their framework of knowledge transfer. Triandis identifies four distinct cultural patterns, namely, vertical and horizontal collectivism, and vertical and horizontal individualism. The horizontal - vertical distinction is very similar to Hofstede's (2001) power distance (PD) dimension. People in vertical cultures tend not to value equality, and to see themselves as different from others in social status. In fact, differences in status are not only accepted, but expected in high power distance cultures (Hofstede, 2001). On the other hand, in horizontal cultures, power distance is low, which implies that differences in status are less pronounced. Bhagat et al. (2002) further suggest that these variations cause differences in preferences for processing and transmitting certain types of knowledge. Because of these differences knowledge transfers between cultures on the opposite end of the continuum (e.g. from a vertical collectivistic country, such as Brazil and China, to a horizontal individualistic one, such as the USA) are likely to be ineffective. However, if there is a match between cultural patterns of the recipient and the source of knowledge, chances are high that the knowledge transferred will be understood and incorporated without difficulty. Bhagat et al. (2002) also put forth that the distinction between horizontal and vertical cultures is useful in explaining cross-border knowledge transfer, because information in vertical cultures usually flows from the top to the bottom, whereas information in horizontal cultures flows in both directions. Similarly, Hofstede (2001) suggests that in high PD cultures information flows are usually constrained by hierarchy, which might lead to an exclusion of lower-level employees from access to certain types of information. Such practices could create obstacles for knowledge sharing within CoP members with different status. Even though not specifically addressing cross-cultural issues, Ipe's (2003) review of knowledge management literature also concludes that power and status determine people's motivation to share and the direction of knowledge flows.

Trompenaars' (1994) findings regarding ascription- versus achievement-oriented cultures might also shed some light on the direction of knowledge flows within online CoPs as well as the assignment of specific roles within the communities, such as experts and managers. In ascription-oriented cultures, status is ascribed by virtue of age, gender, or wealth. To the contrary, in achievement-oriented cultures, such as the USA, status is derived from past achievements, and is not dependent on seniority or how others relate to his or her position in the community. Whereas a person in an ascription-oriented culture is likely to maintain his or her ascription-based position in society independent of his or her own achievements, in achievement-oriented cultures one has to prove his or her talents time and again. Since legitimation (Lave and Wenger, 1991), that is, the way in which one becomes a full member of the community, is usually the result of members earning their status in the community through a history of achievements (Hildreth et al., 2000), people in ascription-oriented 
cultures might have different expectations. For instance, members of ascription-oriented cultures might expect that those higher up in the organizational hierarchy (usually older and more experienced employees), should also assume the role of officially appointed experts and managers of online CoPs.

\section{Assumptions about cultural influences on knowledge sharing}

Since this was an exploratory study, no specific hypotheses for testing were formulated. However, the above literature review helped us formulate a list of potential cultural differences in knowledge sharing patterns. Specifically, we assumed that:

1. In Asian cultures, such values as modesty and the desire to save face would constitute a significant barrier to active participation in online knowledge sharing communities. Posting questions online could be threatening to people, concerned with saving their own face: in an open forum like this, there is always a threat of ridicule. At the same time, responding to questions and making suggestions online could also pose threat to other people's "face": what if the posted question was rather trivial, and the ease with which an answer was found hints at the inquirer's incompetence? Finally, in cultures that put a significant weight on modesty, community members are likely to avoid being too active in online and other open-forum discussions, out of fear of appearing too immodest and boastful.

2. The above considerations could be affected by the generation gap: older people may be more sensitive about "face"; younger people, especially those who are more exposed to global influences, could have higher tolerance for "face-threatening" situations.

3. In more hierarchical and "vertical" cultures top managers' need for control over the information flow, and the desire to restrict access to critical information by lower-level employees could lead to significant organizational barriers to knowledge sharing. Since active participation in online knowledge sharing presumes that individual employees will feel free to post questions and respond to postings without checking with their supervisors first, such behavior could be seriously limited in hierarchical societies.

4. In hierarchical and "vertical" societies higher-level managers may not be participating in online communities, since they would consider these activities to be not in line with their status image. Therefore, they would tend to delegate this responsibility to their secretaries and lower-level employees.

5. Another barrier to participation in online communities could be cultural preference for face-to-face communication, which depends on cultural assumptions about what is polite, and which mode of communication is more conducive to establishing trust.

6. In-group oriented members of collectivist cultures would tend to focus on the needs of various collectivities they belong to, which is why they might be more willing to share what they know with others. At the same time, a potential barrier to knowledge sharing in such cultures could be the sharper distinction made between in-group and out-group members. Put differently, an employee might stay away from sharing knowledge with someone not considered a member of a narrowly defined in-group (even though these employees could be members of the same larger organization they in which they both belong).

7. The levels of information hoarding could vary from country to country. Thus, Michailova and Husted (2003) have found Russian organizations to be characterized by a significant

\section{"It should not be surprising that the creation and transfer of knowledge across cultural boundaries creates additional challenges that need to be addressed."}


level of information hoarding and the lack of information sharing among employees. They believe that this behavior results from the need to cope with significant uncertainty (brought about by rapid economic changes); and the traditionally high respect for hierarchy and power. Therefore, we assumed that in countries characterized by unstable or rapidly changing economic conditions, and by strong hierarchies and power distance, knowledge sharing may be inhibited, and information hoarding could be present within organizations.

\section{Research method}

The study utilized a qualitative methodology, and was based on in-depth interviews and the analysis of online participation records and other relevant materials. Phone or face-to-face interviews, followed up by e-mails and/or additional phone calls, were conducted in Russia, China, and Brazil, and at the US headquarters of Caterpillar. A total of 36 managers and employees have participated. In interviews, the participants were asked a number of open-ended questions, which were intended to generate rich descriptions of knowledge sharing and problem-solving situations and strategies.

The data collected in each of the three countries were coded and analyzed by different researchers independently using the qualitative data presentation and analysis methods proposed by Miles and Huberman (1994), including development of summary sheets for each interview, coding of individual interview data, and coding of the overall data set. For each of the three countries, the lead researcher utilized help from one additional researcher who provided rating reliability checks by independently coding and analyzing samples of interview transcripts. At the final stage, data from the three countries were analyzed together, to detect commonalities and differences between the country sets.

\section{Findings}

Despite the fact that all three countries in this study can be classified as more "collectivistic" than the USA, the study results suggest that the extent to which national culture impacts knowledge sharing differs significantly among these three countries. Thus, employees in China are more likely to shy away from contributing to online community discussions because of worries about face, modesty, and the lack of language proficiency, than are their Russian counterparts. On the other hand, competition among employees is not such a major barrier to knowledge sharing in Russia and Brazil, as it is in China. In the following sections of the article, we present some of the main study findings, and discuss them in light of our earlier assumptions about potential cultural differences.

\section{"Saving face"}

The study suggests that there is a significant difference among the three countries with respect to the "saving face" issue. In Russia, "face" was not perceived as an important factor at all, which was confirmed by both the US expatriates and Russian employees. One comment made by a US expatriate manager illustrated this point:

Russians, in general, are a bunch of tough people; they don't worry that much about "face." If asking questions will help them to do their job better, they will ask no matter what.

Interestingly, contrary to our initial expectations, the issue of face was not as important in China, either. Most employees feel rather comfortable asking questions and contributing to discussions in public, as long as these interactions contribute to improved job performance. Even those who have some concerns about losing face indicate:

l'd better ask [colleagues], and do a good job. It is worse to loose face in front of clients.

Another employee stated that:

I once heard that Chinese were very sensitive to "face." But regardless of culture, nobody likes to be embarrassed in public. Maybe this is a little bigger deal in China, but not a very big deal. Anybody wants to be treated with courtesy and respect. 
However, compared to Russia and Brazil, the issue of face was more prominent, and came up more often in various parts of the interviews. Furthermore, in line with our expectations, "face" was more of a concern for older employees in China.

\section{Modesty}

Cultural expectations related to modesty were an important influence on online participation and knowledge sharing in China. It was pointed out repeatedly in interviews that in Chinese culture it is not acceptable to speak a lot in public and to stand out. A Chinese proverb states:

Making many people aware of a trivial matter is exaggerating.

Influenced by the value expressed in this proverb, Chinese employees prefer to solve minor problems by themselves, without seeking help from others. One interviewee illustrated this by saying:

I think most of us worry too much about our questions, wondering if we are doing a good job. Maybe the question is not so silly, but as a Chinese proverb goes: "we must think three times before we do it," we will think three times (meaning "think very carefully") before posting questions.

In Russia or Brazil the issue of modesty was not as important as in China. Russian or Brazilian employees seemed to be willing to ask questions online and post responses more often, without much concern for being perceived boastful or immodest.

A related issue to modesty is the lack of confidence in language skills (the existing online knowledge sharing system at Caterpillar is in English only). In China, even when Chinese employees had quite strong language skills, they were worried that what they were posting online was not perfectly worded. As a consequence, they were spending too much time trying to improve their writing, or were abandoning these attempts altogether. Once again, Russian employees seemed to be less concerned about the language issue: even those with less than perfect knowledge of English were comfortable posting rather lengthy messages or questions.

Brazilians, on the other hand, were more like Chinese in this respect: concern for being able to clearly and accurately communicate one's words was great, and had influenced many employees' decision not to participate in online discussions, or to strongly prefer an option to contribute in Portuguese.

\section{Competitiveness}

The research results indicate the presence of a powerful barrier to knowledge sharing in China: competitiveness and job-security related fears. Concern about job security was especially prevalent among younger and lower-level professionals. Today's economic conditions in China are extremely competitive, and a widely accepted proverb is "knowledge is power". When people acquire new knowledge, they believe that it is the key to their success and are likely to guard it instead of sharing it. The following quotes illustrate this finding:

As the Chinese economy is opening up and growing fast, the competition in Mainland China is getting fiercer. Competition among colleagues is already very high.

If we are in the same line of work, we are enemies. People are selfish in this sense.

In China there are too many people for "one cake" and so the competition is high. At all levels, people have their struggles. The pressure is high. There is no much tranquility in heart.

Employees are careful about what they say, considering the competition and evaluation.

Many people do not want to share the expertise they get through many years of hard working. The reason for this situation is competition. If you can solve problems others cannot solve, you will be valued and get self-respect. They know sharing is good for all but they do not share because they think they get less than what they need contribute. This is a comparison of personal benefit and cost. 


\section{"The rollout of a knowledge management system in a new country or region should be tailored to values and cultural preferences of employees."}

How do Chinese employees' worries about job security constitute a barrier to information sharing? One participant explained that asking a question would mean admitting that he does not know something, and admitting this would affect his job security. Another respondent concurred:

They do not want their supervisors to know that they do not know something.

Therefore, employees prefer to ask someone they are familiar with, for example, their peers, people with whom they have started to work at the company together.

Despite the fact that Russian economy is also undergoing rapid economic transition and, according to Michailova and Husted (2003), information hoarding, fueled by job insecurity fears is prevalent among Russian employees of western firms, we have not found such concerns among the employees at Caterpillar. Rather, it seemed that the employees believed that their job situation would actually be strengthened by knowledge sharing, since sharing and active participation in community discussions would improve their visibility and perceived uniqueness, usefulness for the organization. Similar to Russian employees, the majority of the Brazilian sample also perceived knowledge sharing as enhancing their prospects of future job promotions.

\section{Authority, seniority and hierarchy}

Although our assumption was that employees from all three countries in this study would pay significant attention to power and hierarchy, we could not find the evidence to support this assumption. When selecting and appointing online community managers and experts in Russia, China, and Brazil, seniority, rank, or age were not the major factors. As one participant put it:

At the end, whether you are qualified to be an expert depends on how good you are professionally.

Especially in younger peoples' eyes, qualification rests on professional knowledge and does not have much to do with status and positions. However, such attitudes to hierarchy and rank could be an artifact of organizational culture: the US headquarters of Caterpillar is characterized by a rather flat, egalitarian, and open culture, and the overseas subsidiaries seem to have significantly assimilated this cultural attribute. The study provided, however, some evidence that the situation must be very different in local organizations - partners of Caterpillar. Thus, comments related to organizational cultures of CAT ${ }^{\circledR}$ dealerships in Russia and China hint at local managers' attempts to control information flows, to channel all the outside communication through top management. As one Chinese dealership employee stated:

As for the feedback on my communication work, I received negative comments from top-level managers. They ask: "Why are you telling people this? We should determine what they should know." Everywhere it is true that managers want to control the information flow.

The final question related to status and power distance is who in the organization is more likely to participate in online discussions: top level managers, middle level managers, or non-managerial employees. Whereas in the US the majority of participants are middle-level managers, followed by non-managerial employees, in all three countries in our study participants have pointed out that not only top managers, but also middle-level managers are less likely to participate. When asked who is most likely to use online communities on a 
regular basis, the respondents indicated that members of the management team would never do this:

If a manager has a secretary, the manager may ask the secretary to search for information and then the secretary may go online to search.

Another interviewee commented:

As far as I have noticed, there is a difference between Chinese employees and foreign employees in joint-venture companies. For the foreign part, almost everybody uses computers, including the general managers. But for the Chinese part, most general managers ask their secretaries to do this for them, especially the older generation.

Brazilian and Russian interviewees made very similar comments.

\section{Preferred modes of communication and information sharing}

Once again, the three countries differed on this dimension. In Russia, employees were very comfortable with e-mail communication, and did not display any particular preference for either face-to-face, or phone communications. One participant said:

We use e-mail a lot, perhaps, even too much: even within the same building, we send emails to one another, instead of going to chat in person.

In China, on the other hand, the order of preference is different: face-to-face communication is the first, followed by phone calls, and by e-mails. A study participant from China pointed out that:

China is more of a people-oriented society and we value face-to-face communication.

Still another participant explained that China is a people-oriented society, where "warm" personal communication is highly valued. Despite the above preferences, Caterpillar employees in China use e-mails the most because of the time zone difference and the high cost of telephone calls.

There is evidence that Caterpillar employees in Brazil are comfortable with e-mail communication, although face-to-face, warm and personal interaction is strongly valued in Brazilian culture. E-mail is often preferred because it creates a documented chain of evidence. There is also an indication that Brazilian dealers may have a stronger preference for face-to-face communication and could be reluctant to post questions online. When asked why Brazilian dealership employees may be reluctant to post online questions, the participants indicated that they might stay away from posting questions because they prefer face-to-face communication. The above findings seem to further support Hall's (1976) distinction between high- and low-context cultures. In high-context cultures, such as China or Brazil, individuals tend to prefer communication channels with high media richness.

\section{In-group and out-group orientation and openness to knowledge sharing}

Cross-cultural literature suggests that members of collectivist cultures tend to be open and willing to share their knowledge with members of their in-group (Chow et al., 2000), but could be strongly distrustful of out-group members. In Russia, the "us" versus "them" distinction was evident from the way Russian Caterpillar employees were discussing their knowledge sharing with local dealers and other partners. However, it seemed that, instead of being loyal to the immediate in-group only (their local office), Russians felt equally proud and fond of their membership in the organization as a whole. Likewise, in China various comments made by study participants suggest that there is a strong in-group orientation, and distrust of outsiders.

With no exception, Brazilian interviewees expressed great enthusiasm for sharing information with others in their organization. At the same time, the in-group and out-group distinction could be a barrier to knowledge transfer from Brazilian employees to dealership employees. For instance, when asked who should be managing local knowledge-sharing communities, nobody wanted US expatriates or local dealers to do the job. Several participants were referring to both of these groups as "outsiders, " even though, in the case 
of local dealers, the nationality is identical, or in the case of US expatriates, they are working for the same organization.

\section{Discussion and research implications}

Since this study investigated knowledge sharing patterns in an online environment, one plausible explanation for lower than expected importance of several cultural values could be that these differences are less pronounced online than they are in face-to-face interactions. For instance, since the organizational status of other community members is unknown, employees might be less hesitant to post a comment or an answer to someone else's question on the discussion board. Given the scarcity of empirical studies specifically addressing the impact of national culture characteristics on online knowledge sharing, there is a definite need to further examine this relationship.

At the same time, more research is needed to identify the influence of organization culture factors in this context as well as the link between the organizational and national culture. As the findings in all three countries have shown, the expected impact of national cultural characteristics was in some cases less pronounced than initially expected, which could be attributed to the fact that the organizational culture was in some instances stronger in shaping individuals' knowledge sharing patterns. Besides the influence of national and organizational culture on online knowledge sharing behaviors, future research could also address the impact of individual psychological traits, gender, or occupational groups.

In addition, the issue of in-group - out-group distinction in online CoP warrants further investigation. Could it lead to the rejection of new community members and does it make the movement from peripheral to a more central participation more difficult? Or is this distinction not as visible as and less relevant in online environments than it is in personal interactions?

The main limitation of this study is that it was conducted among the online community members of one company. The results of the study could be strongly affected by the dominant professional culture of this organization (engineering), the fact that the firm's headquarters is located in the USA, and other factors, unique to this specific case. Therefore, to determine whether the study findings can be applied to online communities of practice in a wide range of organizations, there is a need for conducting similar studies at additional multinational firms of similar size, operating in other industries.

\section{Implications for knowledge management practitioners}

The study results suggest that any rollout of a knowledge management system in a new country or region should be tailored to values and cultural preferences of employees in each of the countries, where corporate KM systems will be used. Specifically, in some countries there is a need for the development of online interfaces, which reflect local preferences for colors, layout, and other design elements; at the same time, employees in other countries may be less sensitive to these issues, or will have preferences, similar to those of the employees of the corporate headquarters. The bottom line is that any introduction of country-specific knowledge sharing systems, websites or online community web pages should be based on a cultural needs assessment, and identification of culture-specific barriers to knowledge exchange.

Furthermore, when developing guidelines for online community usage, and conducting training on acceptable online etiquette, the rules for the development, posting, updating,

\section{"The introduction of country-specific knowledge sharing} systems, websites or online community web pages should be based on a cultural needs assessment, and identification of culture-specific barriers to knowledge exchange." 
and editing of questions and knowledge entries, and the rules for responding to inquiries, $\mathrm{KM}$ managers should not assume that it is enough to translate into various languages the existing corporate manuals and training materials. Instead, they should be aware of a possibility that assumptions about acceptable rules of online community behavior could vary significantly from country to country, and even those procedures, which appear self-evident to the headquarters employees, may need to be carefully explained, or adjusted to local preferences.

\section{References}

Ardichvili, A., Page, V. and Wentling, T. (2003), "Motivation and barriers to participation in virtual knowledge-sharing communities of practice", Journal of Knowledge Management, Vol. 7 No. 1, pp. 64-77.

Ashwin, S. (1996), "Forms of collectivity in a non-monetary society", Sociology, Vol. 30 No. 1, pp. 21-39.

Bansler, J. and Havn, E. (2003), "Building community knowledge systems: an empirical study of IT-support for sharing best practices among managers", Knowledge and Process Management, Vol. 10 No. 3, pp. 156-63.

Bhagat, R., Kedia, B., Harveston, P. and Triandis, H. (2002), "Cultural variations in the cross-border transfer of organizational knowledge: an integrative framework", Academy of Management Review, Vol. 27 No. 2, pp. 204-21.

Branch, R.M. (1997), "Educational technology frameworks that facilitate culturally pluralistic instruction", Educational Technology, Vol. 37 No. 2, pp. 38-41.

Brown, J. and Duguid, P. (1991), "Organizational learning and communities of practice", Organization Science, Vol. 2 No. 1, pp. 40-7.

Chow, C., Deng, F. and Ho, J. (2000), "The openness of knowledge sharing within organizations: a comparative study in the United States and the People's Republic of China", Journal of Management Accounting Research, Vol. 12, pp. 65-95.

Davenport, T. and Prusak, L. (1998), Working Knowledge: How Organizations Manage What They Know, Harvard Business School Press, Boston, MA.

Ford, D. and Chan, Y. (2003), "Knowledge sharing in a multi-cultural setting: a case study", Knowledge Management Research and Practice, Vol. 1 No. 1, pp. 11-27.

Ginsburg, H., Posner, J. and Russell, R. (1981), "The development of knowledge concerning written arithmetic: a cross-cultural study", International Journal of Psychology, Vol. 16 No. 1, pp. 13-35.

Gourlay, S. (2001), "Knowledge management and HRD", Human Resource Development International, Vol. 4 No. 1, pp. 27-46.

Gupta, A. and Govindarajan, V. (1994), "Organizing for knowledge flows within MNCs", International Business Review, Vol. 3 No. 4, pp. 443-57.

Gupta, A. and Godvindarajan, V. (2000), "Knowledge flows within multinational corporations", Strategic Management Journal, Vol. 21, pp. 473-96.

Hall, E. (1976), Beyond Culture, Anchor Press, Garden City, NY.

Hambrick, D., Davison, S., Snell, S. and Snow, C. (1998), "When groups consist of multiple nationalities: towards a new understanding of implications", Organization Studies, Vol. 19 No. 2, pp. 181-205.

Hildreth, P., Kimble, C. and Wright, P. (2000), "Communities of practice in the distributed international environment", Journal of Knowledge Management, Vol. 4 No. 1, pp. 27-38.

Hofstede, G. (2001), Culture's Consequences: Comparing Values, Behaviors, Institutions and Organizations across Nations, 2nd ed., Sage Publications, Thousand Oaks, CA.

Holden, N. (2001), "Knowledge management: raising the spectre of the cross-cultural dimension", Knowledge and Process Management, Vol. 8 No. 3, pp. 155-63.

Hutchings, K. and Michailova, S. (2004), "Facilitating knowledge sharing in Russian and Chinese subsidiaries: the role of personal networks and group membership", Journal of Knowledge Management, Vol. 8 No. 2, pp. 84-94. 
Hwang, A., Francesco, A. and Kessler, E. (2003), "The relationship between individualism-collectivism, face, and feedback and learning processes in Hong Kong, Singapore, and the United States", Journal of Cross-cultural Psychology, Vol. 34 No. 1, pp. 72-91.

Inkpen, A. and Dinur, A. (1998), "Knowledge management processes and international joint ventures", Organization Science, Vol. 9 No. 4, pp. 454-68.

Ipe, M. (2003), "Knowledge sharing in organizations: a conceptual framework", Human Resource Development Review, Vol. 2 No. 4, pp. 337-59.

Kogut, B. and Zander, U. (1993), "Knowledge of the firm and the evolutionary theory of the multinational corporation", Journal of International Business Studies, Vol. 24 No. 4, pp. 625-45.

Korac-Kakabadze, N. and Kouzmin, A. (1999), "Designing for cultural diversity in an IT and globalizing milieu”, Journal of Management Development, Vol. 18 No. 3, pp. 291-324.

Kurman, J. (2003), "Why is self-enhancement low in certain collectivist cultures? An investigation of two competing explanations", Journal of Cross-Cultural Psychology, Vol. 34, pp. 496-510.

Lave, J. and Wenger, E. (1991), Situated Learning: Legitimate Peripheral Participation, Cambridge University Press, Cambridge, NY.

Liedtka, J. (1999), "Linking competitive advantage with communities of practice", Journal of Management Inquiry, Vol. 8 No. 1, pp. 5-16.

Michailova, S. and Husted, K. (2003), "Knowledge sharing in Russian companies with western participation", Management International, Vol. 6 No. 2, pp. 19-28.

Miles, M. and Huberman, A. (1994), Qualitative Data Analysis: An Expanded Sourcebook, Sage Publications, Thousand Oaks, CA.

Mowery, D., Oxley, H. and Silverman, B. (1996), "Strategic alliances and interfirm knowledge transfer", Strategic Management Journal, Vol. 17, pp. 77-91.

Nonaka, I. (1994), "A dynamic theory of organizational knowledge creation", Organization Science, Vol. 5, pp. 14-37.

Pfeffer, J. and Sutton, R. (2000), The Knowing Doing Gap: How Smart Companies Turn Knowledge into Action, Harvard Business School Press, Boston, MA.

Polany, M. (1957), The Tacit Dmension, Anchor Books, Garden City, NY.

Simonin, B. (1999), "Transfer of marketing know-how in international strategic alliances: an empirical investigation of the role and antecedents of knowledge ambiguity", Journal of International Business Studies, Vol. 30 No. 3, pp. 463-90.

Triandis, H. (1995), Individualism and Collectivism, Westview, Boulder, CO.

Trompenaars, F. (1994), Riding the Waves of Culture: Understanding Diversity in Global Business, Irwin Professional Publishing, Burr Ridge, IL.

Walsham, G. (2001), "Knowledge management: the benefits and limitations of computer systems", European Management Journal, Vol. 19 No. 6, pp. 599-608.

Wasko, M. and Faraj, S. (2000), "It is what one does: why people participate and help others in electronic communities of practice", The Journal of Strategic Information Systems, Vol. 9 Nos 2/3, pp. 155-73.

Wenger, E., McDermott, R. and Snyder, W. (2002), Cultivating Communities of Practice: A Guide to Managing Knowledge, Harvard Business School Press, Boston, MA.

\section{About the authors}

Alexandre Ardichvili is associate professor at the University of St. Thomas in Minneapolis, Minnesota. He holds a PhD in Human Resource Development and a MBA from the University of Minnesota, and a PhD in management from the University of Moscow. Alexandre has published more than 30 peer-reviewed articles and book chapters in knowledge management, human resource development, and entrepreneurship. Alexandre Ardichvili is the corresponding author and can be contacted at aardichvili@stthomas.edu

Martin Maurer is a PhD candidate at the department of Human Resource Education at the University of Illinois at Urbana-Champaign. Prior to earning a Master's degree in human resource development at the same institution, Maurer studied business administration at the 
Vienna University of Economics and Business Administration in Austria. His research interest focuses on knowledge management and international human resource development.

Wei Li is a doctoral student in the Graduate School of Library and Information Science at the University of Illinois at Urbana-Champaign. Her research interests include knowledge management, knowledge sharing, and how culture influences people's sharing behavior. She is currently studying the impact of national culture on knowledge management.

Tim Wentling is professor of Library and Information Science at the University of Illinois at Urbana/Champaign, and Senior Research Scientist at the National Center for Supercomputing Applications, where heads the Knowledge and Learning Systems Group. Professor Wentling is author of numerous books and peer-reviewed articles on human resource development, e-learning, and knowledge management. His current research focuses on knowledge management and e-learning.

Reed Stuedemann is manager at the Caterpillar University, where he is responsible for overseeing the corporate knowledge management system. Reed is a regular presenter at leading knowledge management conferences, and has co-authored a number of articles and book chapters on KM.

To purchase reprints of this article please e-mail: reprints@emeraldinsight.com Or visit our web site for further details: www.emeraldinsight.com/reprints 